\title{
ANALISIS PENGARUH PENURUNAN TEMPERATUR PADA PROSES TUANG CAIRAN LOGAM DENGAN COVER LADLE DI PT. $X$
}

\author{
Mohamad Faizal ${ }^{1}$, Hendra Gunawan ${ }^{2}$ \\ Program Studi Teknik Mesin S1, Institut Sains dan Teknologi Nasional, Jakarta Selatan ${ }^{12}$ \\ email $^{1}$ : mfaizalh172@gmail.com
}

\begin{abstract}
Abstrak
Tuliskan abstrak anda di bagian ini dengan indentasi paragraf. Jumlah kata yang baik untuk sebuah abstrak adalah berkisar antara 100-300 kata. Font yang digunakan adalah Times New Roman 11pt. Abstrak berisi tulisan yang mencakup pendahuluan, metodologi dan hasil. Abstrak ditulis dalam bahasa Indonesia dengan baik dan jelas. Penggunaan referensi sebaiknya tidak digunakan pada abstrak. Istilah dalam bahasa lain dicetak miring (italic). Kata-kata kunci atau keywords yang baik tidak lebih dari 7 kata.
\end{abstract}

Kata kunci: abstrak, bahasa, isi, paragraf, font

\begin{abstract}
Block Cylinder is an important component of a vehicle engine where the quality of the component should not be defect because it can affect the function of the vehicle engine. Block cylinder is made from cast iron material (FC 230) which must be melted with temperature $>1400{ }^{\circ} \mathrm{C}$. The temperature of cast iron molten metal into the mold is a very important factor to guarantee final quality of block cylinder. Process pouring of molten metal into a mold using a ladle to pouring 15 molds. Pin hole defects often occur in the final castings, this is due to molten metal temperature drop at the end, the one factor is air convection suction smoke collector. Smoke collector is required to move the gas that arises during the pouring process to outside the factory in order to make a comfortable and healthy work process, but it has side effect speed up decreasing temperature of molten metal. To solve the decrease temperature is minimize the rate of heat transfer that occurs from molten metal to environmental air. One way is to close the ladle with the cover to reduce the heat transfer that occurs in the metal liquid. The material used as a ladle cover is Kaowooltm SZr, where it has low thermal conductivity and light density. The rate of heat transfer occurring in the metal liquid to the surrounding air without cover is 4,5563 $\mathrm{kW}$. After using the ladle cover the rate of heat transfer from metal liquid to air decreases to $1.8287 \mathrm{~kW}$. Then the liquid temperature of the final cast metal rises from $1369^{\circ} \mathrm{C}$ to $1383^{\circ} \mathrm{C}$, and the pin hole defect occurring in the final cast decreases from $0.22 \%$ to $0.12 \%$.
\end{abstract}

Keywords: Pin Hole Defect, Cast Iron, Ladle, Molten Metal Temperature, Cover Ladle

\section{PENDAHULUAN}

Produksi block cylinder yang terbuat dari bahan cast iron FC 230 merupakan komponen utama dari mesin mobil. Proses tuang block cylinder cast iron di PT. X satu ladle digunakan untuk penuangan cairan logam sebanyak 15 cetakan. Cacat pada block cylinder sering terjadi pada tuangan akhir. Kondisi cairan logam dituangan akhir memiliki temperatur yang lebih rendah dari pada tuangan awal karena adanya heat loss. Posisi cacat yang terjadi block cylinder berada pada posisi tight plug cope no. 4 .
Hubungan temperatur akhir yang rendah terhadap posisi cacat di tight plug cope no.4 dikonfirmasi dengan software Magmasoft. Hasilnya area tightplug cope no. 4 mengalami temperatur paling rendah sehingga berpotensi cacat. Karena potensi cacat pada temperatur rendah lebih tinggi, untuk mendapatkan kondisi temperatur seperti fluiditas cairan logam tuangan awal perlu dilakukan pengurangan heat loss cairan logam.

Salah satu heat loss yang terjadi adalah konveksi dari cairan logam ke udara oleh hisapan 
smoke collector saat proses tuang. Untuk menurunkan heat loss tersebut dibuat alat cover ladle untuk mengurangi laju penurunan temperatur cairan logam.

\section{TINJAUAN PUSTAKA \\ Proses Pengecoran Logam (Casting)}

Pengecoran logam adalah suatu proses manufaktur yang menggunakan logam cair dan cetakan untuk menghasilkan bentuk produk yang mendekati bentuk geometri akhir produk jadi. Logam cair akan dituangkan atau ditekan ke dalam cetakan yang memiliki rongga cetak (cavity) sesuai dengan bentuk atau desain yang diinginkan. Setelah logam cair memenuhi rongga cetak dan tersolidifikasi, selanjutnya cetakan disingkirkan dan hasil cor dapat digunakan untuk proses sekunder.

Fluiditas dapat didefinisikan sebagai kualitas cairan logam untuk mengalir melalui bagian-bagian cetakan dan untuk mengisi semua celah dari cetakan, memberikan hasil yang tajam dan bentuk yang sesuai dengan detail desain. Hal ini menunjukkan bahwa fluiditas dapat menjadi faktor dalam casting saluran pendek atau dalam hasil permukaan casting yang buruk. Ini juga bisa dikatakan, fluiditas bukanlah satu sifat fisik dalam arti yang sama dengan massa jenis atau viskositas, tapi karakteristik kompleks yang berkaitan dengan perilaku spesifik kondisi dalam cetakan pengecoran. Dalam mempertimbangkan faktor yang mempengaruhi aliran molten meltal, faktor viskositas mungkin diharapkan lebih dominan.

Perbedaan antara aspek fluiditas dan yang diukur, untuk contoh, dengan tes spiral ditarik oleh Wood dan Gregg12, yang menyatakan :

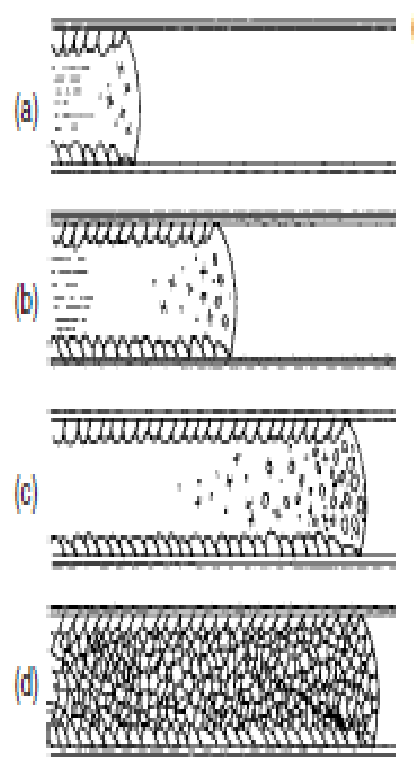

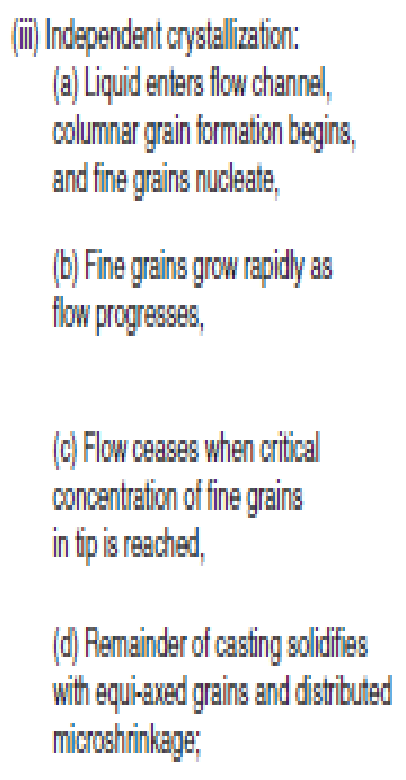

(iii)

Gambar 1 Proses solidifikasi cairan logam

\section{Proses Crystal Growth}

Proses crystal growth yang mengikuti nukleasi menentukan kristalografi akhir struktur padat. Modus growth, baik individual grains dan massa padat secara umum, tergantung pada kondisi thermal di zona solidifikasi dan jenis dari paduan.

Pembekuan logam murni menyajikan contoh yang paling mudah karena temperatur lebur yang sama akan menghasilkan proses solidifikasi secara seragam, berbeda dengan logam paduan karena memiliki temperatur lebur yang berbeda akan terjadi proses solidifikasi yang tidak seragam dari logam cair. Dibawah kondisi praktis aliran panas, bagaimanapun proses solidifikasi menghasilkan gradien suhu nukleasi awal pada permukaan cetakan yang relatif dingin berlanjut ke pertumbuhan (growth) ke arah pusat casting (Gambar 2). Pertumbuhan seperti itu cenderung dikaitkan dengan arah kristalografi, baik kristal yang berorientasi tumbuh lebih cepat dari posisi lain dalam gradien temperatur.

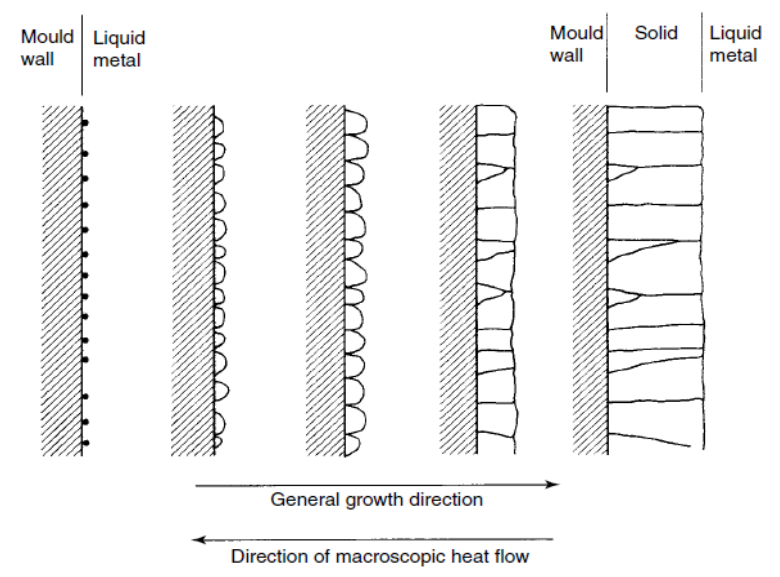

Gambar 2 Pertumbuhan (growth) struktur butiran kolom.

Produksi struktur kolum karakteristik sering diamati pada ingot dan produk coran, dengan butir individu memanjang ke arah umum aliran panas. Kondisi termal yang menghasilkan struktur seperti itu diilustrasikan pada Gambar 3. Diasumsikan adanya suhu positif gradien pada antarmuka padatcair, antarmuka semakin maju karena suhu pertumbuhan tercapai pada titik-titik yang lebih dalam di dalam casting. Pembekuan dapat terjadi saat panas laten kristalisasi tidak cukup untuk membalik arah aliran panas dalam permukaan cairan yang berdekatan.

Dalam banyak kondisi, perpindahan panas dari casting ke cetakan pendingin menghasilkan gradien positif pada skala makroskopik, lokal evolusi panas laten cukup untuk membalikkan gradien suhu pada antarmuka. Kondisi termal dalam kasus ini ditunjukkan pada Gambar 3 Karena suhu 
minimum dalam cairan tidak lagi berdekatan dengan antarmuka, pertumbuhan dengan kemajuan umum dari solidifikasi depan yang halus memberi jalan pada mode pertumbuhan lainnya dimana deposisi dapat terjadi daerah dengan undercooling lebih besar. Aliran panas mikroskopis bisa jadi besar faktor dalam pembentukan struktur cor.

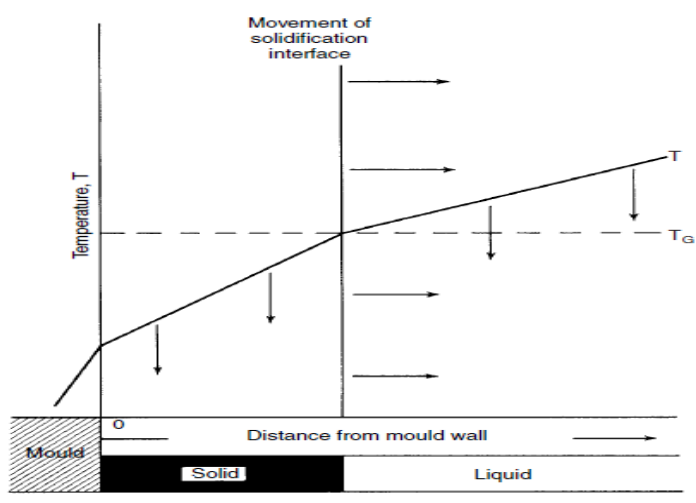

Gambar 3 Skema representasi distribusi temperatur solidifikasi

Crystal growth pada cast iron terjadi dalam 2 tahap, yaitu column growth stage dan central equiaxed region. Gambar 4 menjelaskan terbentuknya column growth stage dan equiaxed growth stage. Microstrukture terjadi pada area equiaxed growth.

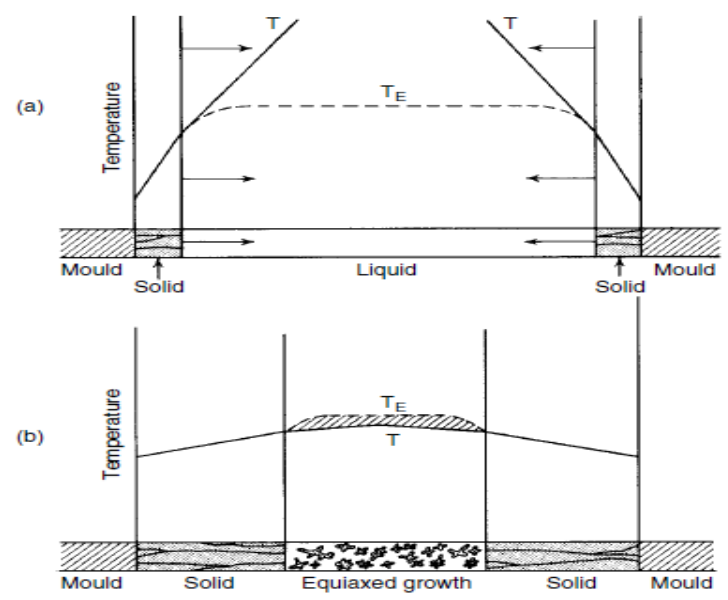

Gambar 4 Column growth stage

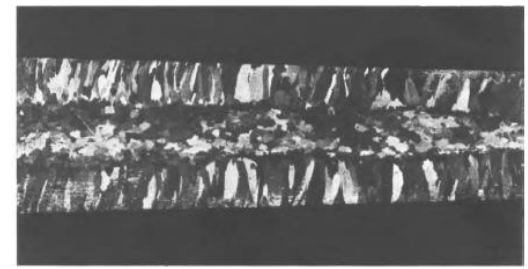

Gambar 5 Macrostructure pada cast iron zona columnar dan zona equiaxed

Gambar 5 menunjukan makrostruktur pada zona columnar dan zona equiaxed. Sample berbentuk tirus dimana ketebalan zona columnar relatif sama, sedangkan zone equiaxed terjadi setelah zona columnar dan mengikuti profil produk.

\section{Perpindahan Kalor secara Konduksi}

Perpindahan energi secara konduksi atau hantaran dan bahwa laju peipindahan panas itu berbanding dengan gradient suhu normal. Konduksi adalah perpindahan panas yang disebabkan oleh kontak langsung dari molekul-molekul benda padat dan pada permukaan tipis dari fluida cair atau gas ke molekul yang terdekat menyebabkan getaran yang memberikan energi kinetik molekul dan selanjutnya dirubah menjadi energi panas. Jika pada suatu benda terdapat gradien suhu (temperatur gradient) maka akan terjadi perpindahan energi dari bagian suhu tinggi kebagian suhu rendah. Kita katakan bahwa energi berpindah secara konduksi atau hantaran dan bahwa laju perpindahan panas itu berbanding dengan gradient suhu normal.

$$
\mathbf{q} / \mathbf{A} \sim \mathbf{d T} / \mathbf{d x}
$$

Jika dimasukkan konstanta proposionalitas,

$q=-\mathrm{k} \cdot \mathrm{A} \cdot \mathrm{dT} / \mathrm{dx} ;$ Untuk Plat datar

$\mathrm{q}=-\mathrm{k} . \mathrm{A} \cdot \mathrm{dT} / \mathrm{dr}$; Untuk tabung atau silinder

Untuk plat datar, seperti yang terlihat pada gambar 2.6.

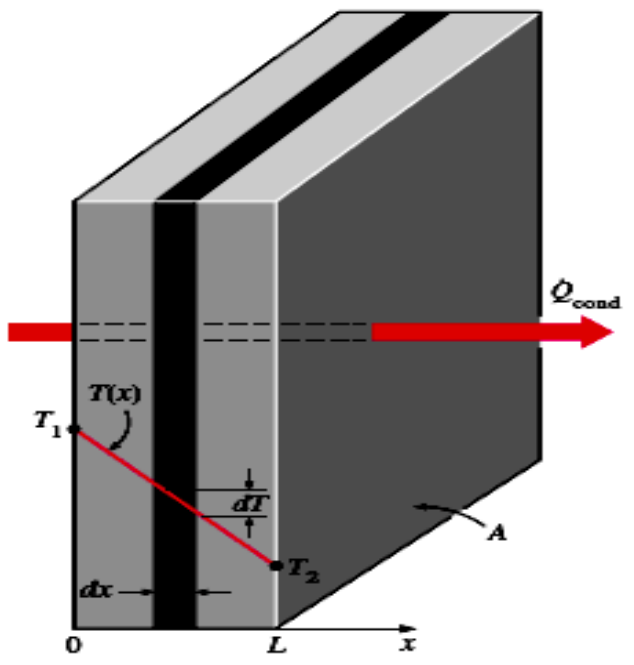

Gambar 6 Konduksi pada plat

$$
\begin{gathered}
Q_{\text {cond }}=\int_{x_{1}}^{x_{2}} d x=-k A \int_{T_{1}}^{T_{2}} d T \\
Q_{\text {cond }}\left(x_{2}-x_{1}\right)=-k A\left(T_{2}-T_{1}\right) \\
Q_{\text {cond }}=\frac{-k A\left(T_{2}-T_{1}\right)}{x_{2}-x_{1}}=\frac{k A\left(T_{1}-T_{2}\right)}{\Delta x} \\
Q_{\text {cond }}=\frac{k A\left(T_{1}-T_{2}\right)}{\Delta x}=\frac{\left(T_{1}-T_{2}\right)}{\frac{x}{k A}}=\frac{\left(T_{1}-T_{2}\right)}{R}
\end{gathered}
$$




$$
Q_{\text {cond }}=-k A \frac{d T}{d x}
$$

Dimana :

$Q \quad=$ Laju perpindahan kalor $(\mathrm{J})$

$k=$ Koefisien panas konduksi $(\mathrm{W} / \mathrm{m} . \mathrm{K})$

$A=$ Luas permukaan aliran panas (m2)

$\Delta T \quad=$ Perbedaan temperatur $(\mathrm{K})$

$\Delta x \quad=\operatorname{Jarak}(\mathrm{m})$

\section{Perpindahan Kalor secara Konveksi Paksa}

Konveksi Paksa yaitu perpindahan panas suatu fluida yang diakibatkan oleh energi luar, misal menggunakan fan. Jenis aliran dalam konveksi paksa adalah laminar dan turbulen. Jenis aliran dapat diketahui dengan menentukan Bilangan Reynold. Untuk Bilangan Reynold aliran di luar saluran aliran:

$$
\begin{aligned}
R e=\frac{\rho \cdot v \cdot L}{u} & =\frac{\text { Gaya inersia }}{\text { viskositas }} \\
\operatorname{Re} & =\frac{V \cdot L}{v}
\end{aligned}
$$

\section{Dimana:}

$$
\begin{aligned}
R e & =\text { Bilangan Reynolds } \\
u & =\text { Kecepatan fluida } \\
v & =\text { Viskositas kinematis } \\
L & =\text { Panjang penampang plat } \\
\rho & =\text { Massa jenis fluida }
\end{aligned}
$$

Aliran Laminer bila $\operatorname{Re}<5 \times 10^{5}$ Aliran Turbulen bila Re $5 \times 10^{5} \leq \operatorname{Rex} 10^{7}$

Lapisan batas thermal adalah daerah dimana terdapat gradient suhu dalam aliran akibat proses pertukaran kalor antara fluida dan dinding, sedangkan lapisan batas hidrodinamis adalah daerah dimana gaya-gaya viskos dirasakan.

\section{Angka Prandtl}

Angka Prandtl adalah parameter yang menghubungkan ketebalan relative antara lapisan batas hidrodinamis dan lapisan batas thermal.

$$
\operatorname{Pr}=\frac{v}{\alpha}=\frac{\mu / \rho}{k / \rho C_{p}}=\frac{\mu C_{p}}{k}
$$

\section{Bilangan Nusselt}

Bilangan yang menghubungkan antara bilangan Reynold dan Angka Prandtl. Untuk menghitung bilangan nusselt pada aliran diluar saluran laminar digunakan persamaan DittusBoelter.

$$
N u=\frac{h \cdot L}{k}=0,664 \operatorname{Re}_{L}^{0,5} \operatorname{Pr}^{1 / 3}
$$

Persamaan diatas hanya dapat digunakan, jika:

$$
\text { - } \operatorname{Re}_{\mathrm{L}}<5 \times 10^{5}
$$

Perpindahan kalor gabungan

Apabila perpindahan panas secara konduksi dan konveksi digabungkan maka akan terjadi seperti pada gambar berikut:

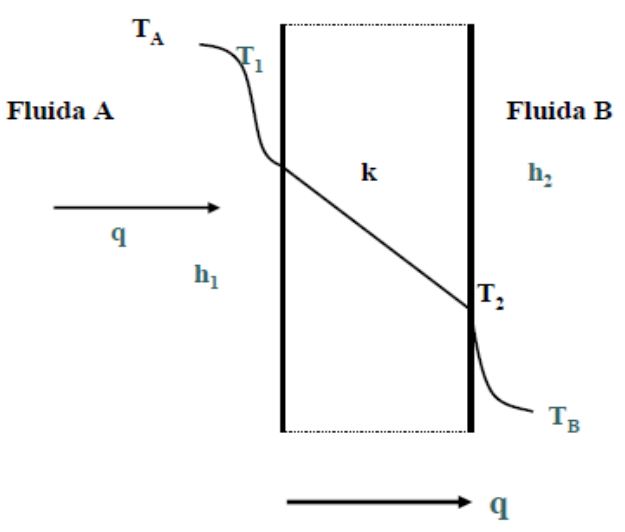

\section{Gambar 7 Laju perpindahan panas konduksi dan konveksi}

Suatu bidang datar, salah satu sisinya terdapat fluida panas A dan sisi lainnya terdapat fluida $\mathrm{B}$ yang lebih dingin.

$$
\begin{aligned}
& \text { Jika } v=\mu / \rho \operatorname{maka} \frac{1}{v}=\frac{\rho}{\mu} \text {; sehingga : } \\
& \mathrm{q}=\frac{\mathrm{T}_{\mathrm{A}}-\mathrm{T}_{\mathrm{B}}}{1 / \mathrm{h}_{1} \mathrm{~A}+\Delta \mathrm{x} / \mathrm{kA}+1 / \mathrm{h}_{,} \mathrm{A}}=\frac{\mathrm{A}\left(\mathrm{T}_{\mathrm{A}}-\mathrm{T}_{\mathrm{B}}\right)}{1 / \mathrm{h}_{1}+\Delta \mathrm{x} / \mathrm{k}+1 / \mathrm{h}_{2}}
\end{aligned}
$$

Selain itu $\mathrm{q}=\mathrm{UA} \Delta \mathrm{T}_{\text {menyeluruh }}$

Sehingga koefisien perpindahan panas menyeluruh dapat dinyatakan dengan:

$$
\mathrm{U}=\frac{1}{1 / \mathrm{h}_{1}+\Delta \mathrm{x} / \mathrm{k}+1 / \mathrm{h}_{2}}
$$

\section{Simulasi Magmasoft}

Simulasi ini ditujukan untuk mengetahui gambaran dari proses pengecoran dari dari produk mulai dari heat transfer yang terjadi di dalam cetakan, porosity, shringkage/penyusutan, dan microstructure dari komponen. Berikut adalah hasil dari simulasi dengan menggunakan software Magmasoft v5.3.

Untuk menjalankan simulasi diperlukan data - data pendukung lapangan seperti geometri produk beserta gating system dan riser, komposisi material, jenis pasir cetakan, sistem saringan, dan temperatur tuang. Langkah pertama yang dilakukan adalah input geometri produk: 


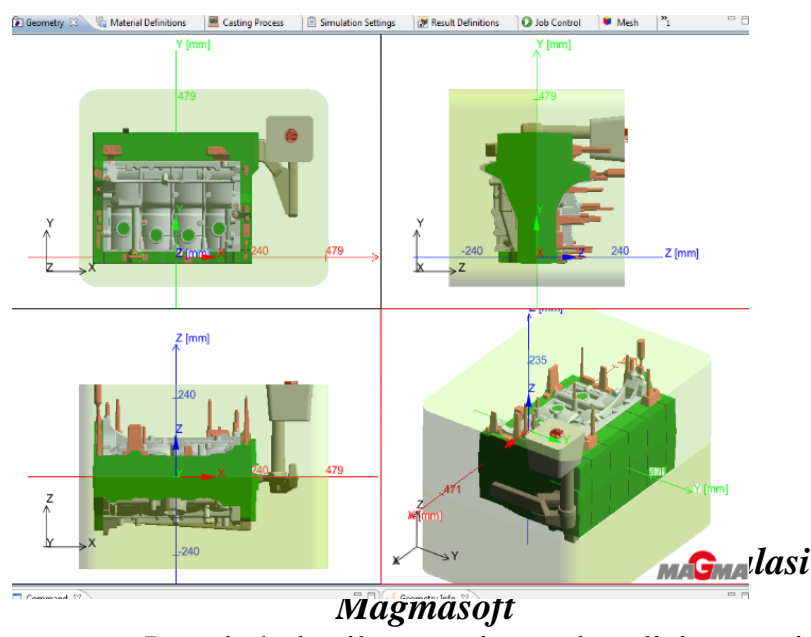

Langkah berikutnya input kondisi material cairan logam seperti komposisi dan temperatur cairan logam. Kemudian pilih jenis pasir cetakan dan temperatur pasir.

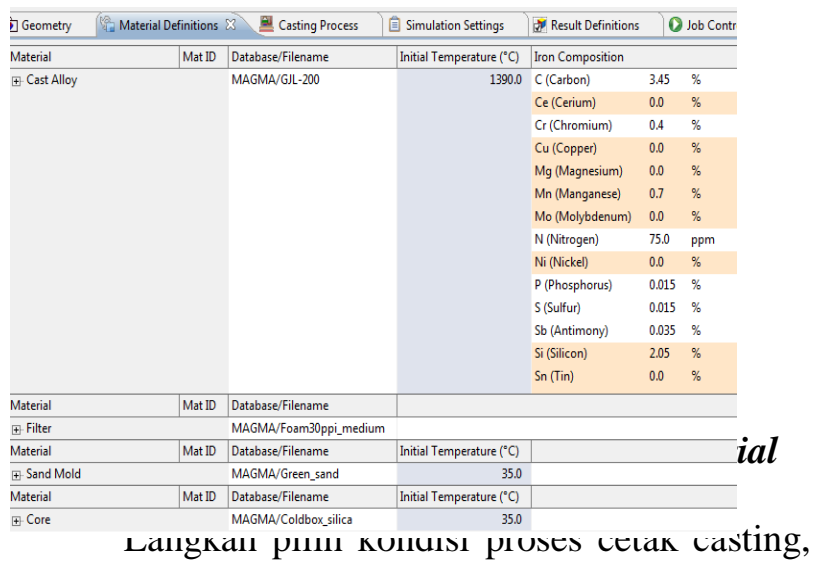

seperti proses inokulasi, kecepatan pouring, dan proses solidifikasi material tersebut.

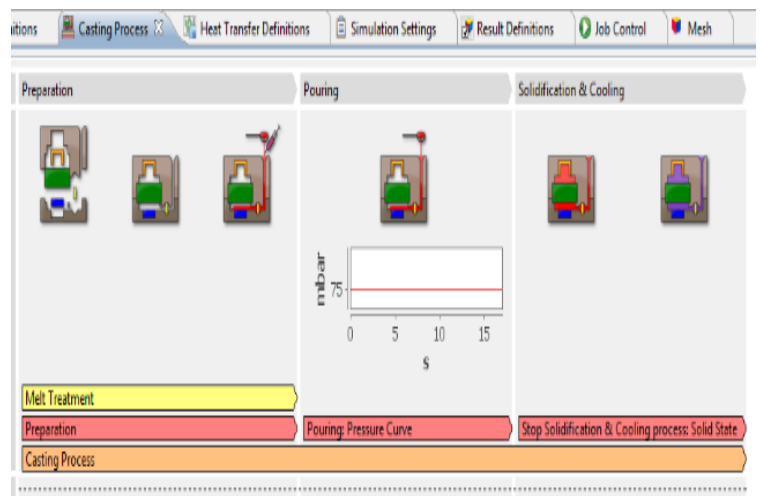

\section{Gambar 10 Proses penggaturan parameter proses casting}

\section{METODOLOGI DAN PENGOLAHAN DATA}

Tahapan proses yang dilakukan pada penelitian ini seperti tergambar pada gambar 11 diagram alir proses pengerjaan

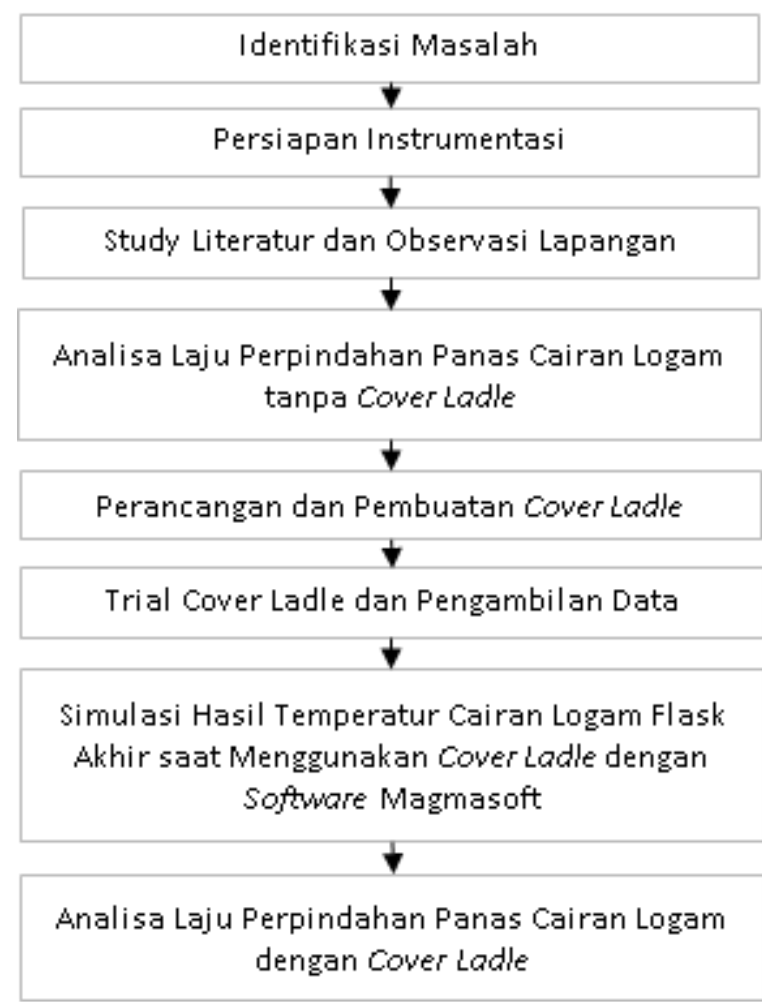

Gambar 11 Diagram alir proses pengerjaan

\section{Prosedur Pengambilan Data}

Pengumpulan data merupakan salah satu tahapan sangat penting dalam penelitian. Teknik pengumpulan data yang benar akan menghasilkan data yang memiliki kredibilitas tinggi, dan sebaliknya. Penelitian dilakukan pada saat unit beroperasi melebur material logam cast iron FC 230. Setelah melakukan observasi dan melakukan pengukuran pada object penelitian. Untuk analisa perpindahan kalor dilakukan pada flask ke-15. Dalam pengambilan data selalu mengutamakan faktor keamanan mengingat kondisi temperatur yang diobservasi cukup tinggi. Berikut langkah-langkah pengumpulan data yang diperlukan

1. Pengukuran dimensi ladle

2. Pengambilan data temperatur cairan logam sebelum menggunakan cover

3. Pengambilan data kecepatan udara yang dihisap smoke collector

4. Pengambilan data dimensi cover ladle

5. Pengambilan data temperatur cairan logam sesudah menggunakan cover

\section{Alat pengukur suhu}

Pada penelitian ini parameter suhu sangatlah penting karena pada keseluruhan penelitian ini banyak membahas mengenai parameter suhu. Pada penelitian ini terdapat 2 jenis alat ukur suhu yang digunakan. Berikut adalah jenis alat pengukur suhu yang digunakan dan spesifikasinya:

- Thermocouple Cairan Logam 
Thermocouple ini digunakan untuk mengukur temperatur cairan logam dengan cara dicelupkan keatas molten.
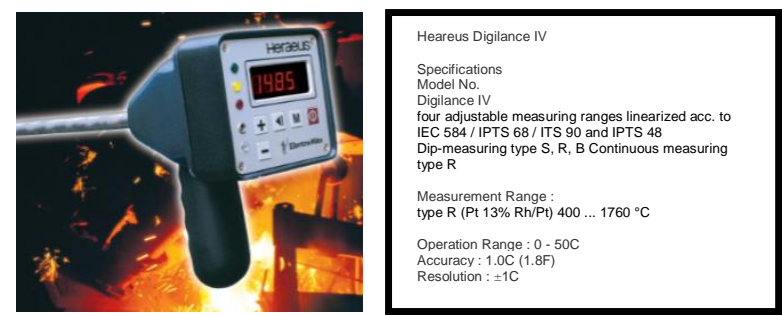

Gambar 12 Thermocouple cairan logam

(Sumber: Manual book molten metal thermcouple)

\section{Non contact infrared thermometer}

Thermometer ini digunakan untuk mengetahui temperatur dinding ladle bagian dalam sebelum dilakukan proses tuang cairan logam ke ladle.
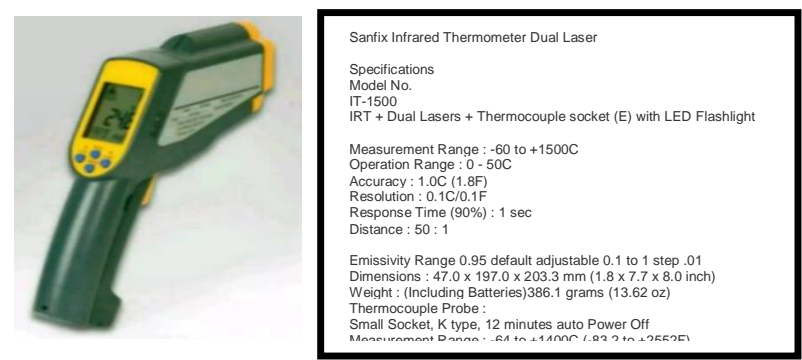

Gambar 13 Infrared thermometerSmartSensor

(Sumber: Manual book infrared thermometer)

\section{Alat Pengukur Kecepatan Udara}

Selain suhu parameter lain yang perlu adalah kecepatan udara disekitar ladle yang dihisap oleh smoke collector. Kecepatan udara sekitar ladle sangat berpengaruh terhadap perpindahan panas secara konveksi yang terjadi dari cairan logam ke udara disekitar. Pada penelitian ini alat ukur kecepatan udara yang digunakan berbasis logger, dimana data hasil pengukuran dapat direkam dalam interval waktu tertentu.
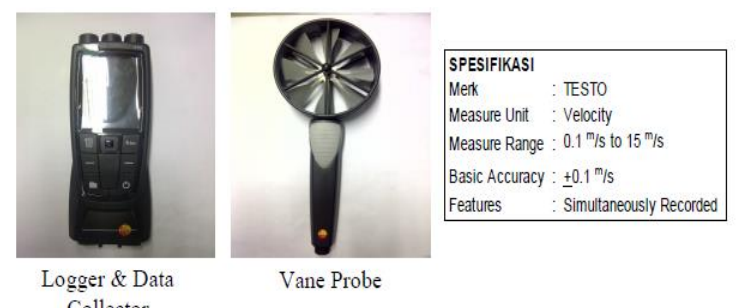

\section{Spesifikasi Data}

Dalam Trial digunakan ladle tuang nomor

17. Setelah melakukan pengukuran dan spesifikasi ladle, maka didapatkan dimensi ladle seperti pada Gambar 11
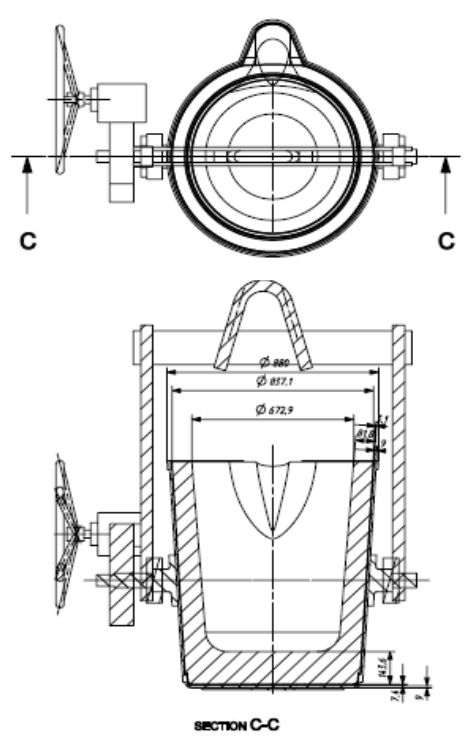

Gambar 15 Dimensi Ladle Tuang (NX 8.0 skala 1:10)

Untuk mengetahui temperatur cairan logam yang masuk ke dalam cetakan dilakukan pengukuran pada saat proses tuang cairan logam ke dalam cetakan. Pengukuran dilakukan setiap 2 flask dari 15 flask untuk mengetahui temperatur cairan yang masuk ke dalam cetakan.

Sebelum dilakukan pengukuran, syarat yang diberlakukan dalam pengambilan data saat sebelum tapping adalah sebagai berikut:

Tabel 1 Data kondisi pengambilan data temperatur tuang

\begin{tabular}{|l|l|}
\hline \multicolumn{1}{|c|}{ Item } & \multicolumn{1}{c|}{ Kondisi } \\
\hline Nama Furnace & $\begin{array}{l}\text { Furnace MF 3.0 Ton } \\
\text { Inductotrem no. 1 }\end{array}$ \\
\hline Line Pouring & Line Pouring A \\
\hline Temp. Tapping & $1470^{\circ} \mathrm{C}$ \\
\hline Berat Cairan & $1272 \mathrm{Kg}$ \\
\hline Temp. Dinding Dalam Ladle & $1045^{\circ} \mathrm{C}$ \\
\hline Temp. Dinding Luar Ladle & $258^{\circ} \mathrm{C}$ \\
\hline $\begin{array}{l}\text { Waktu Handling Cairan } \\
\text { ke Flask 1 }\end{array}$ & $2^{\prime} 23^{\prime \prime}$ \\
\hline
\end{tabular}

Setelah kondisi proses tuang terpenuhi, dilakukan pengukuran cairan logam saat proses tuang ke cetakan. Hasil yang diperoleh adalah sebagai berikut: 


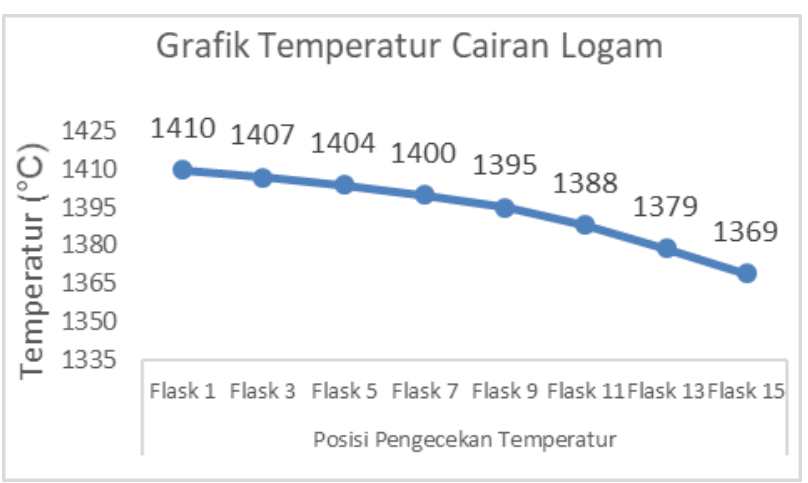

Gambar 16 Grafik temperatur cairan logam saat tuang tanpa cover

Untuk mengetahui perpindahan panas secara konveksi, dibutuhkan data perlu diketahui kecepatan rata-rata aliran udara yang terjadi pada bagian atas permukaan ladle dan temperatur lingkungan ladle. Berikut hasil pengukurannya:

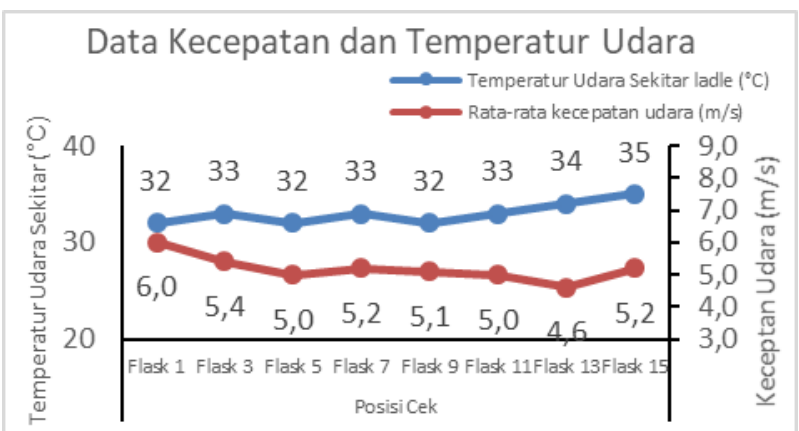

Gambar 17 Grafik temperatur udara dan kecepatan udara smoke

Untuk merancang cover ladle memiliki beberapa standar safety di PT. X agar dapat digunakan secara regular berat total alat yang dibawa $<10 \mathrm{~kg}$ untuk pekerjaan yang bersifat regular dan secara proses tidak mengganggu pekerjaan standar. Proses yang kritis berada pada proses penutupan cover ladle, pengecekan temperatur tidak bisa dilakukan. Oleh karena hal tersebut aliran proses untuk proses cover ladle adalah sebagai berikut :

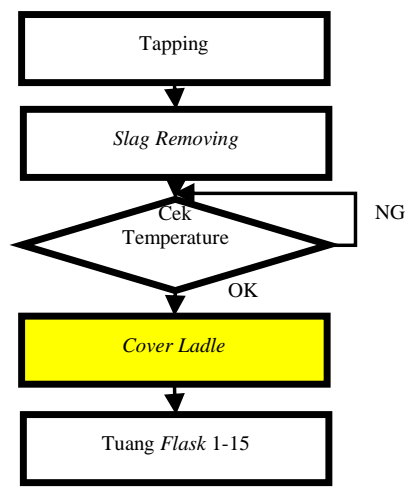

Gambar 18 Aliran proses pengecekan temperatur dengan cover ladle
Dalam menentukan material dasar cover, material yang dibutuhkan adalah memiliki konduktifitas thermal yang rendah dan memiliki berat jenis seringan mungkin dengan tujuan meminimalkan heat loss dan ringan karena digunakan secara manual dengan oleh orang. Berikut adalah data massa jenis material cover ladle:

Tabel 2 Spesifikasi material utama cover ladle

\begin{tabular}{|l|c|c|c|}
\hline Nama Material & Temp. Kerja $\left({ }^{\circ} \mathrm{C}\right)$ & $\begin{array}{c}\text { Berat Jenis } \\
\left(\mathrm{kg} / \mathrm{m}^{3}\right)\end{array}$ & $\mathrm{k}\left(\mathrm{W} / \mathrm{m}^{\circ} \mathrm{C}\right)$ \\
\hline Kaowool $^{\mathrm{tm}} \mathrm{SZr}$ & $>1000^{\circ} \mathrm{C}$ & 96 & 0,23 \\
\hline Ceramic Board & $>1000^{\circ} \mathrm{C}$ & 750 & 0,232 \\
\hline Lining Material & $>1000^{\circ} \mathrm{C}$ & 2750 & 0,95 \\
\hline
\end{tabular}

Dari data table 3.2, material Kaowool ${ }^{\mathrm{tm}} \mathrm{SZr}$ memiliki berat jenis dan konduktivitas thermal yang paling rendah sehingga akan digunakan sebagai dasar perancangan dan pembuatan cover ladle. Selain material utama cover ladle, diperlukan material support sebagai pemegang cover ladle. Berikut adalah material support untuk pembuatan cover ladle.

Tabel 3 Spesifikasi material support cover

\begin{tabular}{|l|c|c|l|}
\hline Nama Material & $\begin{array}{c}\text { Berat Jenis } \\
\left(\mathrm{kg} / \mathrm{m}^{3}\right)\end{array}$ & $\mathrm{k}\left(\mathrm{W} / \mathrm{m}^{\circ} \mathrm{C}\right)$ & \multicolumn{1}{|c|}{ Fungsi } \\
\hline Frame Mild Steel & 7850 & 52 & Untuk frame kaowool \\
\hline Bolt Steel & 7850 & 50,2 & Pengikat frame atas dan bawah \\
\hline $\begin{array}{l}\text { Ceramic Fiber } \\
\text { Cloth IIC 1208 }\end{array}$ & 500 & 0,17 & $\begin{array}{l}\text { Untuk pegangan handle dan frame } \\
\text { agar tidak panas }\end{array}$ \\
\hline Steel Wire & 7850 & 50,2 & untuk mengikat kaowool ke frame \\
\hline
\end{tabular}

Setelah diketahui berat jenis material utama dan material support cover ladle, dilakukan perancangan bentuk dari cover ladle. Konsep dasar pembuatan cover ladle semaksimal mungkin cairan logam bisa tertutup. Masukan dari member tuang area bibir ladle harus tetap dibuka sedikit agar dapat melihat posisi ketinggian cairan saat tuang. Ada beberapa pilihan konsep untuk membuat cover ladle, yaitu:

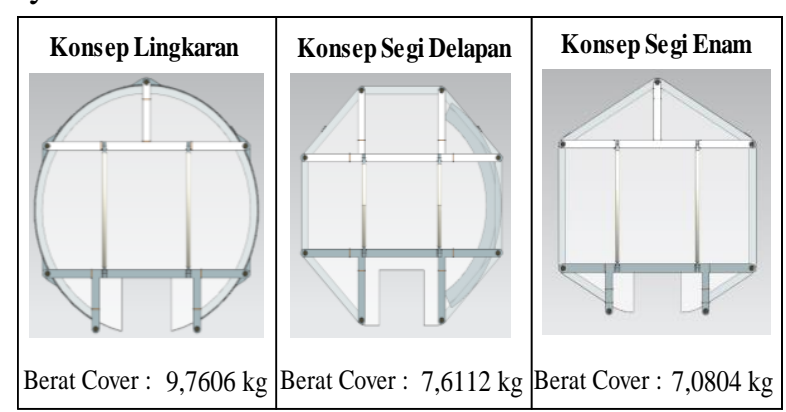

Gambar 19 Konsep cover ladle

Dari data Gambar 16 menunjukan berat total dari cover ladle yang paling ringan adalah konsep segi enam 7,0804 kg. 
Setelah kondisi proses tuang terpenuhi, dilakukan pengukuran cairan logam saat proses tuang ke cetakan. Hasil yang diperoleh adalah sebagai berikut:

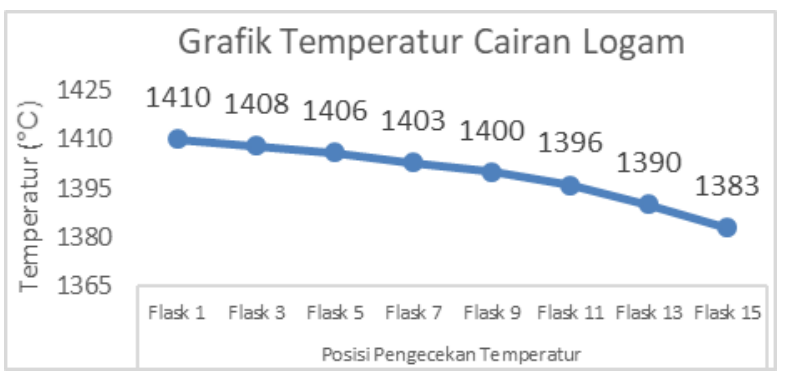

Gambar 20 Grafik temperatur cairan logam saat tuang dengan cover

Untuk mengetahui perpindahan panas secara konduksi dan konveksi pada cover, dibutuhkan data temperatur cover bagian atas dan dalam. Berikut data hasil pengukurannya:

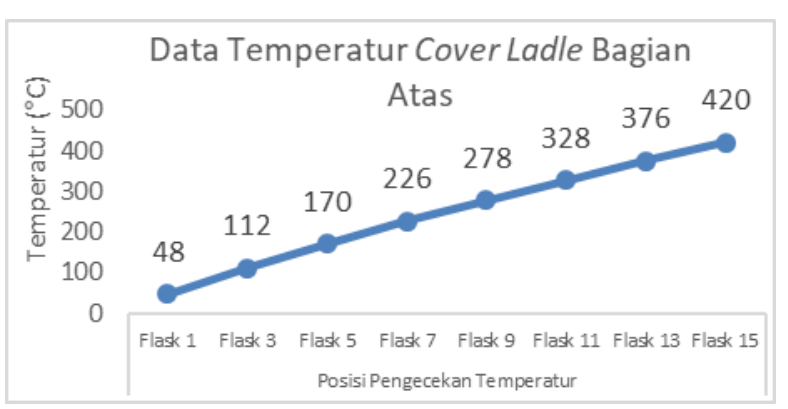

Gambar 21 Grafik temperatur cover ladle bagian atas saat tuang

Selain bagian atas cover ladle, untuk mengetahui perpindahan panas yang terjadi dari cairan logam ke cover ladle, perlu diketahui temperatur bagian bawah cover, karena tidak dimungkinkan untuk mengambil data per dua flask, maka sample data temperatur diambil pada flask ke 15 saja. Berikut hasil pengukuran temperatur bagian bawah cover $506^{\circ} \mathrm{C}$.

Untuk mencari perpindahan panas yang terjadi dari cairan logam ke smoke collector pada flask ke 15 kita harus mencari koefisien perpindahan panas konveksi $(h)$, dengan diketahui;

$$
\begin{array}{ll}
\Delta T & =\left(1369^{\circ} \mathrm{C}+35^{\circ} \mathrm{C}\right) / 2=702^{\circ} \mathrm{C} \\
\rho \text { udara } & =0,3620 \mathrm{~kg} / \mathrm{m} 3 \\
\mathrm{Cp} & =1135 \mathrm{~J} / \mathrm{kg} \cdot{ }^{\circ} \mathrm{C} \\
k & =0,06590 \mathrm{~W} / \mathrm{m} \cdot{ }^{\circ} \mathrm{C} \\
\operatorname{Pr} & =0,7093 \\
v & \left.=1,137 \times 10^{-4} \mathrm{~m}^{2} / \mathrm{s} \text { (pada } 1 \mathrm{~atm}\right) \\
L_{\text {molten }} & =0,6475 \mathrm{~m}
\end{array}
$$

Ketika udara melewati cairan logam secara parallel, Reynold number pada ujung ladle adalah

$$
R e \quad=\frac{V \cdot L}{v}=\frac{\left(5,2 \frac{\mathrm{m}}{\mathrm{s}}\right)(0,6475 \mathrm{~m})}{1,137 x \frac{10^{-4} \mathrm{~m}^{2}}{s}}
$$

$$
=29616,6634=2,9616 \times 10^{4}
$$

Diperoleh bilangan Reynolds dibawah kritis. Dengan demikian aliran laminar diatas cairan logam dan bilangan Nusselt rata-rata menjadi :

$$
\begin{aligned}
N u & =\frac{h L}{k}=0,664 \operatorname{Re}_{L}{ }^{0,5} \operatorname{Pr}^{1 / 3} \\
& =0,664\left(2,9616 \times 10^{4}\right)^{0,5} 0,7093^{1 / 3} \\
& =101,9097
\end{aligned}
$$

Setelah didapatkan Nusselt number, kemudian menghitung koefisien konveksi pada udara yang melewati cairan logam:

$$
\begin{aligned}
h \quad & =\frac{k}{L} N u=\frac{0,06676 \mathrm{~W} / \mathrm{m} \cdot{ }^{\circ} \mathrm{C}}{0,6475 \mathrm{~m}} 101,9097 \\
& =10,3722 \mathrm{~W} / \mathrm{m}^{2} .{ }^{\circ} \mathrm{C} \\
& =0,3293 \mathrm{~m}^{2} \\
\text { As } & \text { h As } \Delta T \\
= & \left(10,3722 \mathrm{~W} / \mathrm{m} \cdot{ }^{\circ} \mathrm{C}\right)\left(0,3293 \mathrm{~m}^{2}\right) \\
& \left(1369^{\circ} \mathrm{C}-35^{\circ} \mathrm{C}\right) \\
= & 4556,3467 \mathrm{~W}=4,5563 \mathrm{~kW}
\end{aligned}
$$

Perpindahan panas yang terjadi antara cairan logam dengan udara sebesar sebesar 4,5563 kW

Kondisi temperatur udara environment sama dengan kondisi ladle tidak dicover dan kecepatan udara smoke collector dianggap sama. Pengolahan data menggunakan perhitungan manual sesuai dengan studi literatur dengan kondisi steady state pada tuangan flask ke 15. Dalam perhitungan cover dianggap menutup semua permukaan ladle.

Berikut adalah perhitungan untuk aliran perpindahan panas dari cairan logam setelah menggunakan cover ladle. Berikut adalah data perhitungan konduksi cover ladle

$$
\begin{aligned}
& Q_{\text {cond }}=\frac{-k A\left(T_{2}-T_{1}\right)}{x_{2}-x_{1}}=\frac{k A\left(T_{1}-T_{2}\right)}{\Delta x} \\
& \Delta \mathrm{T}=\mathrm{T}_{1}-\mathrm{T}_{2}=506-420=86^{\circ} \mathrm{C} \\
& \mathrm{A}=0,3293 \mathrm{~m}^{2} \\
& \Delta \mathrm{x}=38 \mathrm{~mm}=0,038 \mathrm{~m} \\
& k \quad=0,23 \mathrm{~W} / \mathrm{m} .{ }^{\circ} \mathrm{C}
\end{aligned}
$$


Untuk mencari perpindahan panas yang terjadi dari cover ladle ke smoke collector kita harus mencari koefisien perpindahan panas konveksi, dengan diketahui;

$$
\begin{aligned}
\Delta T=\frac{\mathrm{T}_{2}-\mathrm{T}_{3}}{2} & =\frac{\left(420^{\circ} \mathrm{C}+35^{\circ} \mathrm{C}\right)}{2} \\
& =227,5^{\circ} \mathrm{C}
\end{aligned}
$$

$$
\begin{array}{ll}
\rho \text { udara } & =0,7067 \mathrm{~kg} / \mathrm{m} 3 \\
\mathrm{Cp} & =1029 \mathrm{~J} / \mathrm{kg} \cdot{ }^{\circ} \mathrm{C} \\
k & =0,038048 \mathrm{~W} / \mathrm{m} \cdot{ }^{\circ} \mathrm{C} \\
\operatorname{Pr} & =0,6959 \\
v & =3,8048 x \frac{10^{-5} m^{3}}{s} \quad(\text { pada } 1 \mathrm{~atm})
\end{array}
$$

Panjang Molten pada area yang dicover

$$
=0,5699 \mathrm{~m}
$$

Ketika udara melewati cairan logam secara parallel, Reynold number pada ujung ladle adalah

$$
\begin{aligned}
R e=\frac{V \cdot L}{v} & =\frac{\left(5,2 \frac{\mathrm{m}}{\mathrm{s}}\right)(0,6475 \mathrm{~m})}{1,712 \times \frac{10^{-5} \mathrm{~m}^{2}}{\mathrm{~s}}} \\
& =196670,560 \\
& =19,6670 \times 10^{4}
\end{aligned}
$$

Diperoleh bilangan Reynolds dibawah kritis. Dengan demikian aliran laminar diatas cairan logam dan bilangan Nusselt rata-rata menjadi:

$$
\begin{aligned}
N u & =\frac{h L}{k}=0,664 \operatorname{ReL}^{0,5} \operatorname{Pr}^{1 / 3} \\
& =0,664\left(19,6670 \times 10^{4}\right)^{0,5} 0,6959^{1 / 3} \\
& =260,9476
\end{aligned}
$$

Kemudian,

$$
\begin{aligned}
h \quad & =\frac{k}{L} N u=\frac{0,03958 \mathrm{~W} / \mathrm{m} .{ }^{\circ} \mathrm{C}}{0,6475 \mathrm{~m}} 260,9476 \\
& =15,9511 \mathrm{~W} / \mathrm{m}^{2} .{ }^{\circ} \mathrm{C} \\
\text { As } & =0,3293 \mathrm{~m}^{2}
\end{aligned}
$$

Setelah diketahui koefisien konveksi dan konduksi pada cover ladle, maka dilakukan perhitungan koefisien perpindahan panas gabungan sebagai berikut;

$$
\begin{aligned}
U & =\frac{1}{\Delta x / k+1 / h} \\
U & =\frac{1}{0,038 \mathrm{~m} / 0,23 \mathrm{~W} / \mathrm{m} .{ }^{\circ} \mathrm{C}+1 / 15,9511 \mathrm{~W} / \mathrm{m}^{2} \cdot{ }^{\circ} \mathrm{C}} \\
U & =4,3877 \mathrm{~W} / \mathrm{m}^{2} \cdot{ }^{\circ} \mathrm{C}
\end{aligned}
$$

Setelah diketahui koefisien perpindahan panas gabungan, dilakukan perhitungan perpindahan panas:

$$
\begin{aligned}
Q \quad= & U \cdot A \cdot \Delta T \\
Q \quad= & \left(4,3877 \frac{W}{m^{2}} \cdot{ }^{\circ} \mathrm{C}\right) \\
& \left(0,3293 \mathrm{~m}^{2}\right)\left(506^{\circ} \mathrm{C}-35^{\circ} \mathrm{C}\right) \\
Q \quad= & 680,5356 \mathrm{~W}=0,6805 \mathrm{~kW}
\end{aligned}
$$

Perpindahan panas yang terjadi antara cover ladle dengan udara sebesar sebesar $0,6805 \mathrm{~kW}$

Untuk mengetahui dampak kenaikan temperatur cairan logam setelah dilakukan perbaikan dari $1369^{\circ} \mathrm{C}$ menjadi $1383^{\circ} \mathrm{C}$ ke produk, dilakukan analisa secara simulasi software menggunakan program Magmasoft.

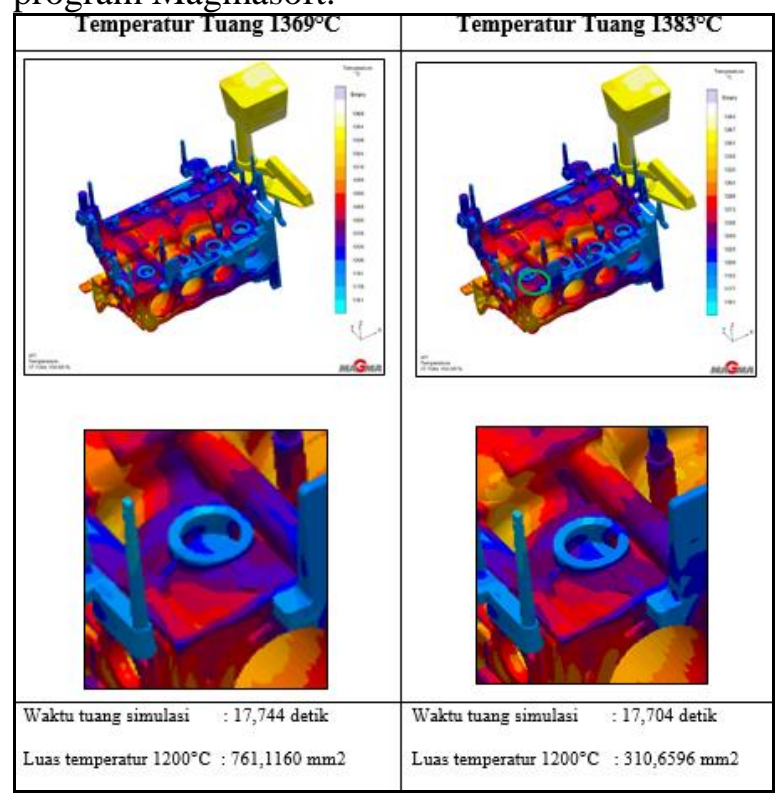

Gambar 22 Perbandingan simulasi temperatur $1369^{\circ} \mathrm{c}$ dan $1383^{\circ} \mathrm{c}$

Jadi,hasil simulasi pada temperatur $1369^{\circ} \mathrm{C}$ memiliki kecepatan tuang 17,744 detik dan luas temperatur $1200^{\circ} \mathrm{C}$ di $761,1160 \mathrm{~mm}$. Hasil simulasi pada temperatur $1383^{\circ} \mathrm{C}$ memiliki kecepatan tuang 17,704 detik dan luas temperatur $1200^{\circ} \mathrm{C}$ di $310,6596 \mathrm{~mm} 2$

\section{ANALISIS DATA}

Setelah mendapatkan data perhitungan laju perpindahan panas yang terjadi pada kondisi ladle tidak dicover dan dicover, terdapat perbedaan laju perpindahan panas yang terjadi, berikut adalah penurunan laju perpindahan yang terjadi pada cairan logam:

Penurunan Laju Perpindahan Panas $(\mathrm{Q})=$ Q tanpa cover - Q tidak dicover 


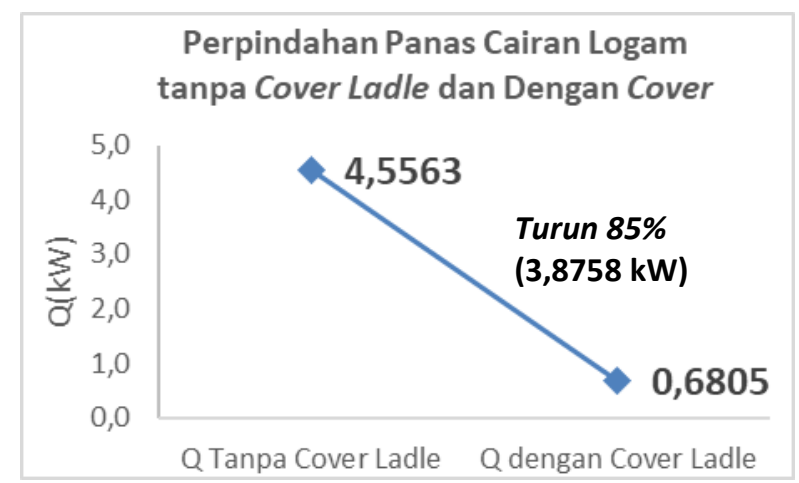

\section{Gambar 23 Grafik penurunan laju perpindahan panas cairan logam dengan cover ladle}

Penurunan laju perpindahan panas yang terjadi setelah menggunakan cover ladle adalah +/$3,87 \mathrm{~kW}$.

Selain membandingkan penurunan laju perpindahan panas yang terjadi setelah menggunakan cover ladle juga dibandingkan perbedaan temperatur tuang di flask ke-15 dengan software simulasi Magmasoft. Temperatur cairan logam yang diperoleh tanpa cover ladle adalah $1369^{\circ} \mathrm{C}$ dan setelah dicover adalah $1383^{\circ} \mathrm{C}$. Dari simulasi berikut diketahui beberapa parameter yang berubah, seperti waktu tuang cairan logam dan luas area temperatur rendah. Berikut adalah perbedaan waktu tuang cairan logam hasil simulasi:

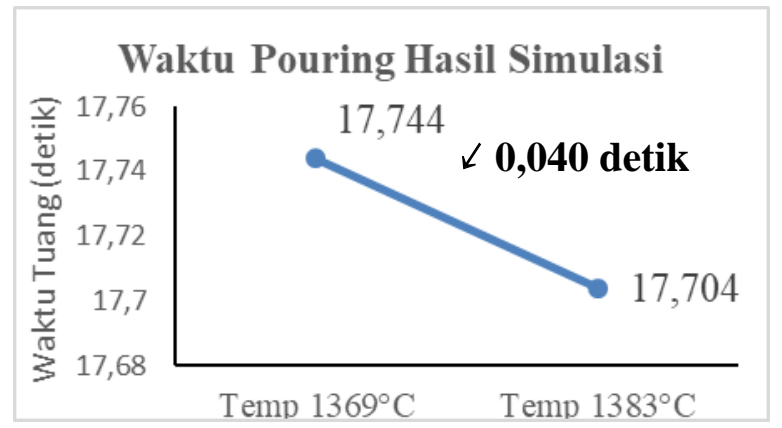

Gambar 24 Grafik penurunan waktu tuang karena kenaikan temperatur tuang

Selain waktu tuang turun, luas area temperatur rendah juga berkurang. Berikut data penurunan temperatur tuang:

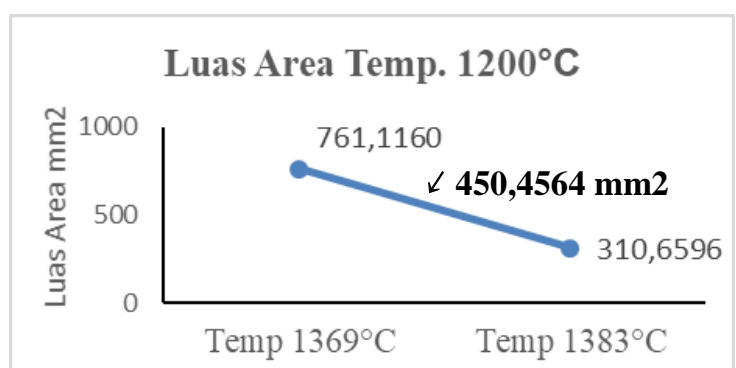

Gambar 25 Grafik penurunan area temperatur rendah karena setelah dicover
Setelah parameter tuang mengalami perbaikan, dilakukan perbandingan kondisi cacat produk tanpa menggunakan cover ladle dan menggunakan cover ladle. Trial dilakukan selama 1 bulan pada bulan Agustus2018 Berikut adalah data cacat yang terjadi pada posisi tight plug 4 cope:

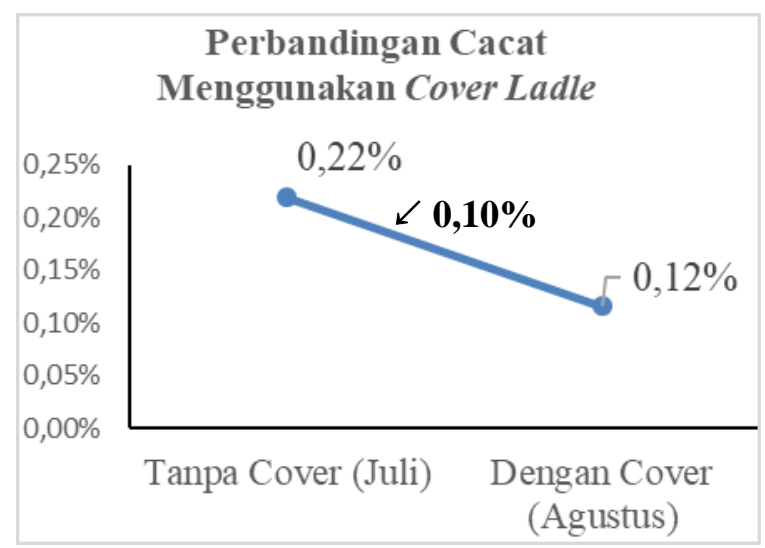

Gambar 26 Grafik perbandingan cacat menggunakan cover ladle

Dengan menggunakan cover ladle pada line tuang cacat pin hole tight plug turun $0,10 \%$ kondisi ladle tanpa di cover.

\section{KESIMPULAN}

Berdasarkan hasil analisa dan pengolahan data dapat disimpulkan:

1. Laju perpindahan panas yang terjadi pada cairan logam ke udara lingkungan pada proses tuang tanpa cover sebesar 4,5563 kW. Laju perpindahan panas yang terjadi pada cairan logam ke udara lingkungan pada proses tuang tanpa cover setelah menggunakan cover ladle adalah $0,6805 \mathrm{~kW}$. Sehingga cover ladle dapat mengurangi laju perpindahan panas yang terjadi pada proses tuang sebesar $3,8758 \mathrm{~kW}$

2. Design cover ladle yang sesuai untuk proses di PT. X terbuat dari material Kaowool ${ }^{\mathrm{tm}} \mathrm{SZr}$ memiliki konduktivitas thermal yang rendah dan massa jenis yang rendah. Untuk bentuk cover yang sesuai adalah menggunakan konsep segi 6 dengan total berat $7,0804 \mathrm{~kg}$.

3. Setelah menggunakan alat cover ladle temperatur cairan logam di flask akhir naik $14^{\circ} \mathrm{C}$ . Dari hasil simulasi waktu tuang turun 0,040 detik/flask dan luas area temperatur rendah dari hasil simulasi awal turun $450,4564 \mathrm{~mm}^{2}$. Hasil akhir cacat pin hole area cope tight plug 4 turun dari $0,22 \%$ ke $0,12 \%$.

\section{DAFTAR PUSTAKA}

Beeley, P. (2001). Foundry technology. Elsevier. 
Cengel, Y. A., \& Boles, M. A. (2002). Thermodynamics: an engineering approach. Sea, $1000,8862$.

Kathait, Dashrath Singh (2016). Heat Loss in Ladle Furnace. Vol. 03 number 07,July 2016. Diambil dari: https://www.irjet.net/archives/ V3 /i7/IRJET-V3I7305.pdf (20 Agustus 2017)

Urquhart, R. C., Guthrie, R. I. L., \& Howat, D. D. (1973). Heat losses from ladles during teeming. Journal of the Southern African Institute of Mining and Metallurgy, 74(4), 132-139.

Dr, E. G. Hoel, C.M. Ecob and D.S White (2005). Heat Conservation In Liquid Iron. Elkem Foundry Products

Nunes, Rafael (2004). Metals HandBook volume 15CASTING. Ebook

Marrone, R. E., Wilkes, J. O., \& Pehlke, R. D. (1970). NUMERICAL SIMULATION OF SOLIDIFICATION. PT. 2. LOW-CARBON STEEL CASTING-L SHAPE. CAST METALS RES J, 6(4), 188-192.

Holpman, J.P., Heat Transfer $10^{\text {th }}$ edition, McGraw-Hill Book Company, Inc., New York, 2010.

Yunus, Asyari D., Diktat Perpindahan Panas dan Massa, Universitas Darma Persada, Jakarta, 2009.

Mitrakusuma, Windy, H., Diktat Dasar Refrigerasi- B2 Termodinamika dan Perpindahan Panas, Paper.

Yoder, John A, DOE Handbook - Primer on Lead Acid Storage Batterie, Department of Energy, Washington, D.C, 1995. 